\title{
Calles y casas de \\ Santa María de la \\ Antigua del Darién
}

\section{Streets and Houses of Santa María de la Antigua del Darién}

DOI: https://doi.org/I0.22380/20274688.1536

Recibido: 8 de septiembre del 2020

Aprobado: 18 de febrero del 2021
CAROLINA QUINTERO AGÁMEZ*

cquinteroa@unal.edu.co

ALBERTO SARCINA**

Instituto Colombiano de Antropología e Historia

asarcina@icanh.gov.co

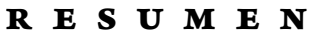

En 1510 se fundó la primera ciudad española en Tierra Firme sobre un poblado indígena llamado Darién, de habla cueva, en el lado occidental del golfo de Urabá. Esta ciudad, a la que los europeos llamaron Santa María de la Antigua del Darién, se convirtió cuatro años después en la capital de Castilla del Oro y llegó a tener aproximadamente 5000 habitantes entre españoles e indígenas. La ciudad contaba con iglesia catedral, plaza principal, hospital, plaza de abastos, Casa de la Contratación, monasterio de San Francisco y cárcel, entre otras edificaciones. De los resultados de las excavaciones arqueológicas se ha podido identificar la ubicación

* Historiadora de la Universidad Nacional de Colombia, magíster en Museología y Gestión del Patrimonio de la Universidad Nacional de Colombia donde también trabaja. Sus proyectos más recientes son: Museología del Parque Arqueológico e Histórico de Santa María de la Antigua del Darién y Curaduría de la Sala Comunitaria del Museo Arqueológico e Historia de Santa María de la Antigua del Darién. Hace parte de la agrupación Museología Comunitaria del Darién.

** Arqueólogo egresado de la Universidad La Sapienza de Roma, Ph. D. en Arqueología en la Universidad de Leiden (Países Bajos). Especialista en Arqueología Estratigráfica y Documentación Arqueológica. Investigador del Instituto Colombiano de Antropología e Historia, donde lidera el proyecto Santa María de la Antigua del Darién y el proyecto del Catálogo de Cerámica Arqueológica de Colombia, del cual es creador. Profesor de Arqueología Estratigráfica en la Universidad de Antioquia y en la Universidad Externado de Colombia. Orcid: 0000-0002-1 40I-0539 
de la ciudad y de sus diferentes fundaciones, sin embargo, no se cuenta con un plano de la época que permita entender con precisión su distribución. Este artículo tiene como objetivo empezar a entender la conformación urbanística, el desarrollo y la vida en esta ciudad, por medio de fuentes históricas.

Palabras clave: Darién, Santa María de la Antigua del Darién, ciudad colonial, urbanismo colonial, cuadrícula, primeras fundaciones españolas, Colombia colonial

\section{$\begin{array}{llllllll}\mathbf{A} & \mathbf{B} & \mathbf{S} & \mathbf{T} & \mathbf{R} & \mathbf{A} & \mathbf{C} & \mathbf{T}\end{array}$}

In 1510, the first Spanish city on Tierra Firme was founded on an indigenous village called Darien, from a Cueva speaking population, on the western side of the Gulf of Urabá. This city, which the Europeans called Santa María de la Antigua del Darién, became four years later the capital of Castilla del Oro and it got to have approximately 5000 inhabitants between Spaniards and natives. The city had a Cathedral Church, main square, hospi- tal, food market, Casa de la Contratación, Franciscan monastery and prison, among other buildings. From the results of the archaeological excavations it has been possible to identify the location of the city and its different foundations, however, there is no map of the time that allows a precise understanding of its distribution. This article aims to understand better the urban configuration, development and daily life in this city, through historical sources.

Keywords: Darién, Santa María de la Antigua del Darién, colonial city, colonial urbanism, grid, first Spanish foundations, colonial Colombia

\section{Introducción}

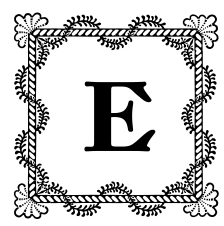

1 proyecto arqueológico Santa María de la Antigua del Darién, impulsado por el Ministerio de Cultura y el Instituto Colombiano de Antropología e Historia (ICANH) desde el 20I3, ha permitido identificar tres momentos fundacionales en el lugar: el primero sería la población prehispánica cueva llamada Darién; el segundo corresponde a la conquista espańola del mismo asentamiento en I5IO; y el tercero, la fundación oficial de la primera ciudad en Tierra Firme y capital de Castilla del Oro, que implicaría una expansión: Santa María de la Antigua, en I5I4 (Sarcina, "Santa María de la Antigua del Darién, la primera ciudad española”). Sin embargo, no se cuenta con un plano o mapa de la época que permita entender con precisión su distribución. 
En esta contribución no nos interesa relatar nuevamente la historia de la primera ciudad castellana en Tierra Firme de América, más bien, el objetivo es intentar comprender mejor la distribución urbanística de la capital de Castilla del Oro y, en la medida de lo posible, proponer algunos indicios de cómo se desarrollaba la vida cotidiana en su interior.

Para ello, se dispone de importantes fuentes primarias, por ejemplo, las crónicas de ilustres habitantes de la ciudad de Santa María de la Antigua como Gonzalo Fernández de Oviedo y Pascual de Andagoya, o documentos de otros ciudadanos, entre ellos cartas, probanzas, cédulas reales y cargos recopilados en libros de destacados historiadores como José Toribio Medina, Juan Friede, Severino de Santa Teresa, Manuel Serrano y Sanz y Martín Fernández de Navarrete. También se cuenta con la narración contemporánea de otros cronistas como Pedro Mártir de Anglería o Bartolomé de Las Casas, que escribieron en la distancia a partir de noticias recibidas por los viajeros en Tierra Firme. Ninguno de ellos proporciona jamás una descripción clara de la ciudad, nadie dice cuántas calles o plazas tenía. Es preciso basarse en una serie de indicios que se desprenden de la narración principal de estos autores.

\section{La vida en Santa María}

La primera fundación de Santa María, en I5IO, no se realizó en un lugar despoblado. Su asiento fue sobre el poblado del cacique Cemaco, de lengua cueva, utilizando sus bohíos y labranzas. El nombre de este asentamiento indígena, como señala Fernández de Oviedo, era igual al del río que le corría al lado: "[...] y estaba muy gentil población, y con un hermoso río que passa pegado a las casas de la ciudad, de muy buena agua y de muchos buenos pescados. Este es el rio del Darién" (Fernández de Oviedo, Historia general 3: 33) y "El río que por allí passa y el pueblo tenían un mismo nombre" (Fernández de Oviedo, Historia general 2: 427). No queda duda, entonces, de que el poblado del cacique Cemaco se llamara Darién, así como el territorio de su cacicazgo, nombrado por los españoles “provincia del Darién” (Fernández de Oviedo Historia general 2: 415; Sarcina, "Santa María de la Antigua y Darién. Las dos caras" 246-247).

Según los resultados de las recientes investigaciones arqueológicas, este poblado se hallaba en las alturas del sitio, tres principales y otras cinco más reducidas, en un patrón de asentamiento de grupos de casas familiares con huertas relativamente alejadas de otros grupos ubicados en la misma altura 
o en otras (Sarcina, De la gloria I52-154). En I5IO, los españoles al mando de Balboa y Enciso ocuparon las principales de estas alturas, y establecieron el primer asentamiento. Con la llegada de Pedrarias Dávila en I5I4 y las aproximadamente 2000 personas que lo acompañaban, la ciudad se expandió hacia los bajos anegadizos entre las colinas y las otras alturas del sitio (Sarcina, De la gloria 155-164), tratando de organizar el asentamiento según las disposiciones de la Corona para las nuevas fundaciones en Tierra Firme.

\section{El poblado de Balboa, la primera etapa de la ciudad colonial (1510-1514)}

El pueblo quedaba a legua y media del mar, en la ribera del río Darién (Andagoya 84), un río pequeño por el cual no podían navegar los grandes barcos, pero sí las pequeñas embarcaciones, para abastecer con las provisiones que llegaban al Toldo, la bodega del puerto marítimo (Fernández de Oviedo, Historia general 3: 37). A pesar de contar con las construcciones y el trabajo indígena, había muchas dificultades y escasez de alimentos ("Carta al rey", cit. en Medina 2: I29).

En los primeros cuatro años, en Santa María de la Antigua habitaban alrededor de 500 españoles y unos I 500 indios de servicio llamados naborías (Fernández de Oviedo, Historia general 3: 33-36). Oviedo contó cien casas a la llegada de la armada de Pedrarias Dávila; doscientos es el número que apuntó el obispo Quevedo (“Carta del obispo de Darién al rey, 6-I5I5”, cit. en Medina 2: 436).

Debido a la escasez, Vasco Núñez de Balboa, líder fundador de la ciudad, estableció alianzas, a partir de la intimidación, con algunos caciques, para obtener alimentos y esclavos. Los caciques, a fin de mantener la tranquilidad en sus poblados, enviaban mensajeros con presentes: pescado, puercos de monte y pavos (Quevedo, cit. en Santa Teresa 40: 280).

Después de más de tres años, la ciudad tenía entre cien y doscientas casas, había cultivos de maíz y yuca en sus alrededores; tenía algunos hatos de puercos y se había conseguido tener bienestar sin muchas pretensiones: cuando llegó la armada del nuevo gobernador, Pedro Arias de Ávila o Pedrarias Dávila, a Santa María en I5I4, Balboa vestía de manera muy sencilla y dirigía la construcción de una casa: "lo hallo vestido de una camisa de algodón y calzado de alpargatas, dirigiendo a ciertos indios que le techaban con paja un buhío" (Las Casas, cit. en Medina I: 139). El obispo Quevedo también relata cómo encontró el pueblo a su llegada: 
Vasco Núñez con el regimiento nos recibió y nos aposentó con muy buena gracia, y dio de comer al gobernador y a mí y a otros muchos, largamente. Hallamos este pueblo bien aderezado, más de doscientos bohíos hechos, la gente alegre y contenta, cada fiesta jugaba cañas y todos estaban puestos en regocijo. (Quevedo, cit. en Santa Teresa 40: 280)

Las viviendas estaban construidas al estilo indígena, pero estaban habitadas por los españoles y sus indios de servicio. Según la descripción de Oviedo, existían dos tipos de casas indígenas en La Española: caney y bohio. El caney era redondo y el bohio estaba hecho a dos aguas. Ambas tenían paredes de cañas atadas con bejuco y techo de paja. A diferencia de La Española, las casas indígenas en Darién eran todas a dos aguas (Fernández de Oviedo, Sumario 134). A medida que el poblado iba creciendo y se hacían nuevas construcciones, los españoles hicieron sus propias modificaciones: pusieron puertas, ventanas y segundo piso a sus casas, para lo cual utilizaron clavos. La cocina se mantuvo al estilo indígena: un bohío aparte más pequeño ("Probanza 1520", cit. en Friede I: 69).

Los indígenas dormían en hamacas de algodón, de muy buena calidad y distintos tamaños y grosores, con cordeles de cabuya y henequén que ataban a los árboles con sogas de algodón (Fernández de Oviedo, Sumario 138). Posiblemente, algunos españoles dormían en hamacas y otros dormían en camas, según sus posibilidades.

En I513, Vasco Núñez, quien no tenía muy buena reputación en Europa (Fernández de Oviedo, Historia general 3: 4), ya sabía de la existencia de otro mar gracias al cacique de Ponca, y decidió aventurarse en su búsqueda. Mientras tanto, en España se preparaba la armada más grande que hasta entonces hubiera cruzado el Atlántico, para llegar a Castilla del Oro y convertir a Santa María de la Antigua en el centro y el control de los nuevos descubrimientos, a cargo de un nuevo gobernador. 


\section{La ciudad de Pedrarias Dávila, la segunda etapa de la ciudad colonial (1514-1524)}

En I5I4, la llegada del nuevo gobernador Pedrarias Dávila, y aproximadamente $2000^{\mathrm{I}}$ personas de Sevilla (Fernández de Oviedo, Historia general 3: 33-36), generó un súbito desequilibrio entre las posibilidades de producción de alimentos y el gran número de habitantes. Con la gran armada habían llegado provisiones para tres meses, que luego fueron vendidas a precios elevados aprovechando la necesidad, seguramente con la aprobación del gobernador y sus oficiales ("Relación de 1516", cit. en Medina 2: 430). Esto provocó la reacción de algunos de los habitantes, que quemaron el Toldo con todas las provisiones que contenía (Fernández de Oviedo, Historia general 3: 37), lo que ocasionó una gran crisis en el primer año, puesto que no había suficientes alimentos, y coincidió con un periodo de malas cosechas y plagas. La gente moría de hambre y circulaban las enfermedades (Las Casas, cit. en Santa Teresa 40: 285). En ese primer año murieron entre seiscientos y setecientos europeos (Andagoya 85-86).

Sumado a las enfermedades y el hambre, los pobladores empezaron a tener pleitos sobre los solares y las viviendas. Se les habían quitado casas a algunos pobladores para dárselas a otros, y muchos que no tenían terrenos asignados construían dentro de solares ajenos (Quevedo, cit. en Santa Teresa 4I: 3I2).

El rey Fernando dio instrucciones sobre la distribución de la tierra, los solares debían ser repartidos según los méritos de cada uno y se le debía dar prioridad a los que habían ido con Ojeda, Nicuesa y Enciso:

Aveys de dar y señalar al escudero y persona que vos haya servido y sirviere y se avecindare allá, por repartimiento de tierras en que pueda poner y señalar doscientos mil montones, y esto se llama una caballería de tierra, y al peón a razón de cien mil montones que es una peonia, y a este respeto los solares, y para solares en que hagan sus casas y buyos los habéis de señalar y dar suelo de cien pasos en largo y ochenta de ancho, a las personas susodichas, y a las otras personas que fueron de menos

I Carmen Mena (76) pudo calcular, gracias al estudio de los documentos oficiales, el número de pasajeros que estaban anotados para embarcar: i 250 personas. Sin embargo, como ella misma lo aclara, este número pudo variar en las paradas y esperas que se hicieron y el margen de error entre las anotaciones legales y las personas que de verdad se embarcaron. Por tanto, es más preciso hablar de los que llegaron, que de los que salieron. Oviedo, quien estaba presente en Santa María, habla de aproximadamente 2000 . 
calidad o condición o merecimiento a este respecto. ("R. C. I513", cit. en Santa Teresa 40: 232)

Para poder disponer de la tierra, las viviendas y encomiendas de indios, se debía tener por lo menos cuatro años de residencia en Santa María. Los residentes también podían comercializar oro, plata, perlas y explotar minas durante diez años, todo con licencia del gobernador y el descuento del quinto para la Corona (“R. C. I5I3" cit. en Medina I: I04).

Algunos españoles tenían encomiendas de indios dentro y fuera de Santa María. En el caso de que estuvieran dentro de la ciudad, en vista de las dificultades, se permitía que dos españoles administraran una encomienda en una misma casa (Espinosa et al., cit. en Santa Teresa 4I: 43I-432). Los encomenderos solicitaron que las encomiendas fueran de por vida, que se heredaran, y que solo se quitaran por justa causa (Fraile Francisco, cit. en Friede r: 94).

Con la armada llegaron personas de diferentes oficios como caballeros, artesanos y agricultores (Fernández de Oviedo, Historia general 3: 4-6). Muchos dejaron sus ocupaciones al llegar a Tierra Firme para dedicarse a las nuevas empresas colonizadoras: la esclavitud y el oro. También llegaron algunas mujeres españolas que viajaron con sus hijos y maridos.

No hay muchos datos sobre mujeres españolas en el Darién antes de I5I4, aparte de Inés de Escobar, viuda de Juan Quiceno, quien "fue recomendada por el Monarca al Gobernador, y se le dio permiso para vender las caballerías de tierras y solares que había obtenido el difunto" (Serrano y Sanz cccxiv).

Las mujeres indígenas eran capturadas en las entradas ${ }^{2}$ y separadas de sus familias, para convertirlas en naborías o esclavas. Generalmente, debían trabajar en los bohíos y también ayudaban en la edificación de casas y en los cultivos (Santa Teresa 40: 283). Algunas veces, los mismos caciques ofrecían a las mujeres de su linaje a los españoles para generar alianzas o para apaciguarlos:

[...] (Careta) en señal de lo cual le daba una de sus hijas por mujer, la cual era muy hermosa, y que para que su gente tuviese lugar de hacer labranzas y sementeras para le proveer, que le ayudase contra el señor y cacique Ponca, que era su enemigo. Aceptó Vasco Núnez la dadiva y las promesas, y holgóse mucho con la hija, la cual tuvo por manceba,

2 Expediciones de exploración y saqueo en los diferentes cacicazgos de la zona. 
puesto que Careta no entendió dársela sino por mujer, como se acostumbraba entre ellos. (Las Casas 4: 75)

Se había permitido, en algunos casos, que españoles e indígenas se unieran en matrimonio, y varias de estas uniones eran reconocidas por la Corona para asegurar los bienes de los difuntos (“Carta I529”, cit. en Medina 2: II5).

Cuando Pedrarias Dávila llegó a Darién, iban con él su esposa, Isabel de Bobadilla, y sus doncellas de servicio, muchas de las cuales se casaron con los expedicionarios que allá se encontraban (Santa Teresa 40: 275). De igual manera, muchos caballeros importantes venían con sus familias. Por ordenanza del rey, en el viaje de la armada se les había concedido a cien hombres viajar con sus mujeres e hijos (“R. C. I5I3", cit. en Serrano y Sanz cCCxxix).

Para los viajes a Tierra Firme, se puso límite al vestuario y los adornos que debían llevarse. A Pedrarias Dávila se le dio una real cédula que moderaba el exceso de lujo en la indumentaria, con el objeto de economizar el oro que se estaba gastando en brocados, sillas, espadas y prendas de vestir, y detener el empobrecimiento de los expedicionarios ("Carta del rey, I5I3", cit. en Serrano y Sanz cclXxxvir). Sin embargo, el gobernador y su esposa Isabel podían llevar sin límite seda, oro, brocado o cualquier vestuario que quisieran transportar (“R. C. I5I3", cit. en Medina 2: 58).

Como lo había pedido Balboa en su carta de 1513, luego de enfrentamientos con los bachilleres Enciso y del Corral ("Carta de Vasco Núńez de Balboa”, cit. en Medina 2: 138), durante los primeros cuatro ańos se prohibieron los abogados, para permitir mayor libertad a sus habitantes. No se aceptaría ningún juicio por escrito y todos los debates se determinarían por el buen juicio y el libre albedrío de los varones (“R. C. I5I3", cit. en Serrano y Sanz CCLXXI).

El rey también dio instrucciones al gobernador sobre el lugar que debía destinarse para erigir la plaza y la iglesia, al igual que el orden de las calles (AGI, Patronato, I-5-II/II, cit. en Santa Teresa 4O: 322). Sin embargo, gran parte de la ciudad, construida sobre el poblado indígena, ya tenía su propia distribución. Para la organización y la administración se asignaron los cargos oficiales de tesorero, contador, factor, veedor, alguacil y alcalde mayor, entre otros (Las Casas 4: 164).

La postura del gobernador con relación a las poblaciones nativas fue muy distinta de la de Balboa. Pedrarias Dávila, excapitán de guerras africanas, al darse cuenta de que la producción de la ciudad no daba abasto para todos sus habitantes, aplicó una estrategia bélica clásica: movilizar constantemente 
a una parte de los habitantes armados en incursiones por el territorio, en busca de riquezas (oro y esclavos) y autosubsistencia. Estos pequeños ejércitos en movimiento, en misiones que duraban semanas o meses, tenían que proveerse su propio sustento y, de este modo, no constituían una carga para la ciudad. Esta técnica, que en Europa se había utilizado durante siglos, tuvo un efecto devastador en los nuevos territorios americanos, donde las técnicas de guerra eran completamente diferentes (Sarcina, De la gloria 20-2I). Balboa escribió al rey en 1515 sobre las matanzas indiscriminadas a caciques y señores principales, los robos y la esclavización de poblaciones enteras por parte del gobernador y su gente ("Carta al rey", cit. en Navarrete 3: 375).

La Corona, para frenar los excesos cometidos contra los nativos, dictó unas ordenanzas que ponían en regla los atropellos, sin que se viera afectada su economía esclavista. Estas ordenanzas consistían en dar un mejor trato a los indígenas y adoctrinar en la fe católica a los que estuvieran en paz con los cristianos. Al servicio de los españoles debía estar únicamente una tercera o cuarta parte de la población nativa, que debía rotarse cada dos meses para evitar tantas muertes ("Instrucciones del rey", cit. en Las Casas 4: I4O-I4I). Poco se acataron estas ordenanzas al pie de la letra. El cronista Antonio de Herrera y Tordesillas describe así lo que ocurría en las entradas:

véase á cuantos asaron y quemarón vivos, á cuántos echaron a los perros bravos que lós comiesen vivios, á cuantos mataron, porque estaban gordos, para secalles el unto para curar las llagas de los castellanos, á cuantos degollaron, que encadenados llevaban cargas, porque se cansaban é por non quitalles las argollas; pues solo el Licenciado Espinosa, teniente de Pedrarias, que como se falla en los papeles reales, era el espíritu de Pedrarias é ambos el furor de Dios, mató en pocos días, en una entrada, sobre cuarenta mil hombres é metió dos mil captivos en el Darién [...] (Herrera, cit. en Medina 2: 552-553. Énfasis con cursiva añadido)

En las entradas, los españoles obtenían o robaban diversas piezas de oro trabajadas por los indígenas. Todo debía ser fundido y marcado en la Casa de la Fundición, así la Corona tenía un mayor control de lo que ingresaba y circulaba (Medina 2: 500). El veedor de las fundiciones era Gonzalo Fernández de Oviedo, y todo lo que se fundía era anotado de la siguiente forma:

En la ciudad de Santa María de la Antigua, en 2 de Abril, en la Casa de la Fundición en presencia de los dichos contador, veedor y escribano de minas, el gobernador Pedro Arias de Ávila metió a fundir una aguililla 
y una ranilla de oro, labrado de los indios, que dijo que se le había dado una naboría suya, que pesaron in pesos y 6 tomines. ("Alonso de la Puente, I5I4-I520", cit. en Medina 2: 404)

En general, el oro era fundido, pues no tenía otro valor para los españoles más que su peso. En una ocasión, Pedrarias Dávila fundió cierta cantidad de oro para hacer una cadena que portaría como símbolo de autoridad ante los indígenas en el viaje que iba a realizar para "pacificar y castigar" a los caciques de Comogre, Tumanabá y Pocorosa (“Alonso de la Puente, I5I4-I520”, cit. en Medina 2: 407).

Los esclavos se vendían en Santa María o se llevaban a La Española. De una entrada que hizo Gaspar de Espinosa, llegaron 2000 esclavos indígenas encadenados al Darién, para ser comercializados en La Española (Herrera, cit. en Medina 2: 54I). La custodia de los esclavos de la Corona estaba a cargo de Blas de Bastos, quien los herraba y los mantenía en su casa mientras se subastaban públicamente ("Información, I520", cit. en Friede I: 6I).

De los documentos en relación con pérdida de indios hay algunas narraciones sobre esclavos que se escapaban; tal es el caso de un grupo de indios al mando del indio Gasparico, que fueron un día a pescar, como solían hacerlo en la canoa del tesorero para traer cangrejos para la comida, y escaparon todos sin que nadie lograra encontrarlos ("Información, I520", cit. en Friede r: 63-64).

Los niños indígenas recibían educación cristiana. Para los hijos de los caciques "se dispone que sean enseñados en el arte de la gramática e otras cosas de ciencias" ("R. C. I5II", cit. en Santa Teresa 40: 433). También en las casas de los particulares españoles se educaron niños indígenas. En el memorial que Rodrigo de Colmenares presentó al rey se solicita, entre otras cosas, que los espańoles tuvieran la posibilidad de llevar a Castilla dos indios y dos indias de los que se criaban en las casas, pues tenían la posibilidad de ser "buenos cristianos" (AGI, Patronato, 2-2I/I4, cit. en Santa Teresa 4O: 45I).

Los conflictos entre Balboa y Pedrarias Dávila generaron molestias entre algunos pobladores, quienes decidieron enviarle una carta al rey dando cuenta de la situación: "ni el Obispo, ni Pedrarias, ni Vasco Núñez son para los cargos que tienen, por lo que han escripto" ("Oficiales de Tierra Firme, I515”, cit. en Medina 2: 247).

Para dar fin a la enemistad, el obispo Quevedo sugirió una alianza entre Balboa y Pedrarias Dávila por medio de una promesa de matrimonio entre Balboa y la hija mayor del gobernador, doña María, quien nunca estuvo en el 
lugar. A pesar de no contar con la presencia de la novia, se hicieron todas las ceremonias que se requerían para formalizar el casamiento. Una vez realizada la alianza, Pedrarias Dávila envió a Balboa a que se estableciera en Acla (Las Casas 4: 230-23I).

A finales de 1515 Santa María había superado la crisis y ya era una ciudad más organizada. Incluso, el mismo año, el gobernador escribió al rey que la ciudad estaba en un buen sitio, con pastos, riberas y tierras para sembrar que aunque no está en alto, tiene buenos aires y que la principal, cosa porque adoleció tanta gente, fue por no saber aprovecharse de la agua, que se ha hallado ser mejor reposada, y también por la pestilencia general en aquellas partes. (“Carta de Pedrarias, I5I5", cit. en Santa Teresa 40: 289)

Oviedo también informaba que una vez pasada la crisis, la tierra estuvo muy sana y había buenos cultivos, minas de oro a tres y cuatro leguas de la ciudad, y que de los ríos se obtenía buena pesca. Había grandes hatos de puercos, venados y otros animales (Fernández de Oviedo, Historia general 3: 38 ).

Aparte de los puercos, las gallinas y los perros, había otros animales traídos de Espańa, como las vacas y los caballos, que servirían como transporte en las entradas y trabajo de carga. El rey ordenó llevar cien yeguas a Castilla de Oro para que los indígenas no tuvieran que hacer todo el trabajo de carga (“Instrucciones del rey", cit. en Serrano y Sanz cccxxvir). De Europa también habían llevado varias especies de plantas y árboles que, según Pedrarias Dávila, se habían adaptado bien ("Carta de Pedrarias", cit. en Medina I: I8I). El rey había solicitado que con la armada se enviaran personas que supieran labrar la tierra, con todo lo necesario para que fuera productiva. El trigo y la cebada no podían faltar, y se tomaron todas las precauciones en los barcos para su conservación ("Instrucciones del rey", cit. en Serrano y Sanz cClxxxv).

La ciudad seguía creciendo y cada vez había más casas. Sin embargo, no había quien construyera los barcos:

se había muerto la mayor parte de los aserradores y carpinteros y de los oficiales para hacer navíos no quedaba ninguno, que eran, precisamente, los que más falta hacían, pues sin ellos no se podía fabricar para descubrir la Mar del Sur, como el Rey lo tenía ordenado. ("Carta de Pedrarias", cit. en Medina I: I8I) 
En esa época, los juegos de azar como naipes o dados estaban prohibidos pues iban contra la moral cristiana. Los capitanes de las expediciones debían prohibirlos a bordo de los barcos (A. H. de Tucumán, serie I, 3: 160, cit. en Santa Teresa 4I: 45). El gobernador había recibido instrucciones directas del rey sobre prohibir los juegos de dados y naipes, con castigos y multas para quienes desobedecieran ("Instrucción del rey 1513", cit. en Medina 2: 5I). Oviedo, cuando tuvo la ciudad a su cargo, consideró los juegos como delito e impuso castigo con cárcel, por lo cual confiscó todos los juegos y naipes que encontró en el pueblo y los quemó públicamente en la plaza, además, prohibió el consumo de carne los sábados (Fernández de Oviedo, Historia general 3: 7I).

El ajedrez, en cambio, tenía algunos adeptos como Pedrarias Dávila, que era uno de los más aficionados y hacía torneos en el pueblo. Las Casas refiere que, en ocasiones, el gobernador se emocionaba tanto que apostaba cien o hasta quinientos indios en una partida (Las Casas, cit. en Medina I: v).

Diversos intereses impulsaron a Pedrarias Dávila a trasladar la capital de Castilla de Oro a Panamá, ubicada a orillas del Mar del Sur. En un principio, muchos espańoles que tenían sus casas y terrenos en Santa María se resistieron a trasladarse, pero finalmente el rey permitió mover la cated ral al lugar escogido por el gobernador (Las Casas 5: 205).

Pedrarias Dávila nunca había tenido el control total de Santa María, pues Balboa seguía teniendo muchos seguidores. Esta enemistad le costó la vida a Balboa, quien fue decapitado por orden del gobernador en I5I9 en la ciudad de Acla, "e aquí se vido claramente quel Gobernador quería despoblar el Darién, asi porque lo había ganado e poblado Vasco Nuñez, su yerno, a quien había degollado" (Fernández de Oviedo, Historia general 3: 65-72).

Condenar a muerte a Balboa y mover las instituciones a Panamá significó el declive de Santa María de la Antigua. Oviedo relata cómo entre I52I y I523 la población iba disminuyendo paulatinamente, y en 1524 estaba casi completamente abandonada. Los mismos indígenas esclavizados y "otros que con ellos se juntaron”, mataron a sus amos y quemaron la ciudad (Fernández de Oviedo, Historia general 3: II4-II5). 


\section{Los edificios y los espacios de Santa María de la Antigua}

\section{Los espacios públicos y religiosos}

La plaza principal

La plaza principal quedaba frente a la iglesia y era un lugar de reuniones y de pregones públicos, la gente era convocada allí con trompetas ("Acuerdos, I5I4", cit. en Medina 2: 498).

En una ocasión, Balboa tuvo cuatro prisioneros unos días en una pequeña jaula en el medio de la plaza, hasta que fueron liberados y se refugiaron en el monasterio de San Francisco (Fernández de Oviedo, Historia general 2: 47I-478). El hecho de que la plaza ya apareciera en las crónicas sobre Balboa y que su casa quedara sobre una de sus calles, quiere decir que la plaza debió delimitarse desde los primeros ańos.

Por ordenanza del rey, para la iglesia de Santa María de la Antigua se señalaron cuatro solares, al igual que otros solares para la casa de contratación y fundición. Pedrarias Dávila solicitó que se le aprobaran solares para él y sus oficiales (“Carta de Pedrarias, I5I5", cit. en Medina 2: 22I).

\section{Las calles}

En los acuerdos hechos por Pedrarias Dávila, el obispo y los oficiales se menciona la necesidad de hacer mantenimiento y construcción de algunos caminos, entre ellos el de la ciudad al puerto (“Acuerdo, I5I4", cit. en Santa Teresa 4I: 46). El capitán Andrés de Garavito, por ejemplo, ayudó a quitar el monte de los alrededores de la ciudad y de las calles, en la construcción de nueve casas, la iglesia, como también a abrir caminos que hacían falta dentro de Santa María ("Defensa", cit. en Santa Teresa 4I: 44).

En las recientes investigaciones arqueológicas se han encontrado dos tramos de la calle más occidental de la ciudad. Esta calle tenía una anchura que oscilaba entre los 2 y los 2,5 $\mathrm{m}$ y estaba formada por varias capas de pequeñas piedras de río, con un espesor de entre 5 y $10 \mathrm{~cm}$. Su curso no era perfectamente recto, sino que seguía la morfología del lugar. A partir del descubrimiento de una capa de barro antiguo encima del empedrado de la calzada, se dedujo que 
había un problema de "encharcamiento" en esta parte de la ciudad, que también afectaba a las calles (Sarcina, De la gloria 93-IO3).

En las investigaciones sobre la calle occidental se pusieron en evidencia cuatro fases principales de la ciudad de Santa María de la Antigua, por lo menos en sus zonas de bajos anegadizos: una primera fase, de arreglos previos, con la realización de empedrados de grandes dimensiones para el drenaje de las zonas más húmedas y encharcadas; una segunda fase, de construcción de la calle y un edificio de grandes dimensiones en madera; una tercera fase, de decadencia, en la cual el edificio ya estaba parcial o completamente derruido y nuevos charcos eran tapados con fragmentos de ladrillos sacados de casas abandonadas; y una última fase, de abandono de la ciudad (Sarcina, De la gloria 93-I03). La fase de decadencia corresponde probablemente al paulatino abandono de la ciudad ocurrido después de la fundación de Panamá en I5I9 por parte del gobernador Pedrarias Dávila y el traslado de las principales instituciones públicas y religiosas.

\section{Iglesia catedral}

La iglesia se había construido en nombre de Santa María de la Antigua, la virgen que se veneraba en Sevilla, sobre la casa del cacique Cemaco (Anglería I04). Esta primera construcción debió de ser muy sencilla y posiblemente conservaba, de manera parcial, la estructura de la casa del cacique.

Por medio de una cédula real, el rey Fernando ordenó que la iglesia catedral de Santa María se construyera con suntuosidad y a la mayor brevedad posible (“R. C.", cit. en Santa Teresa 40: 378-379). Pedrarias Dávila señaló para la iglesia cuatro solares en medio de la ciudad

[...] y le dotó para la fábrica della, dos caballerías de tierra, y antes que se hiciese, le dio ciento cincuenta castellanos de renta para la fábrica y desto y de lo que la iglesia tenía se ha hecho una honrada iglesia de la manera de allá. (AGI, Patronato, I-I-I/26, cit. en Santa Teresa 40: 377)

La catedral, terminada en 1515 , ocupaba un gran espacio y tenía torre y campanario, con al menos dos campanas (Medina I: I7I-I72).

El sacristán era quien debía encargarse del oficio de tesorero, cerrar y abrir la iglesia, tocar las campanas, encender las velas y tener listo el pan, el vino y todo lo necesario para la ceremonia "comprándolo de la fábrica de la iglesia, con el parecer del cabildo" (AGI, Patronato, I-4-3/8, cit. en Santa Teresa 4I: 304). Esto indica que dentro del terreno de la iglesia se fabricaban algunos víveres. 
Las campanas de la iglesia tenían la función de transmitir mensajes a los habitantes de la ciudad y marcar los ritmos del día. Según la forma en que se tocaban, podían indicar la celebración de eventos religiosos, como la misa, el bautismo o el matrimonio, o bien alertar sobre peligros como incendios o ataques de enemigos: cuando se tañían las campanas, la gente debía reunirse en la plaza frente a la casa del gobernador; cuando las dos campanas se tocaban sin cesar, significaba que la ciudad estaba siendo atacada por los indígenas y todos debían salir con sus armas. Las personas que no salieran ante el llamado, debían pagar una multa de diez pesos de oro, de los cuales se repartía la mitad para las obras públicas de la ciudad y la otra mitad para la cámara y fisco del rey, además de pagar diez días de cárcel; cuando se tocaba solo una campana por posas $^{3}$, significaba que había fuego. En tal caso, la gente debía salir con hachas para cortar leña y vasijas con agua para apagar el fuego. Las personas que no se hicieran presentes debían pagar una multa de cuatro pesos de oro para las obras públicas de la ciudad. También era obligatorio que todos los pobladores de Santa María salieran a la calle armados con sus espadas, de lo contrario se les imponía una pena de dos pesos de oro por cada vez que fueran encontrados sin ellas (“Acuerdos, I515”, cit. en Medina 2: 497).

En ese tiempo el canto y la música religiosa eran muy importantes. El rey había ordenado que de la hacienda real se hicieran unos órganos y un reloj para la iglesia (AGI, IO9-I-5, cit. en Santa Teresa 40: 386).

Como en un principio los espańoles eran pocos, se dio la orden al tesorero y al contador de que mientras no hubiera diezmos, se le pagara al obispo Quevedo 2000 pesos de oro, que era una buena cantidad en la época. Para el atuendo litúrgico, los ornamentos de la iglesia y otros objetos, se le solicitó a Sancho Malienzo, tesorero de la casa de la Contratación de Sevilla, que los comprara (“Ordenanza del rey, 20-8-I5I3”, cit. en Serrano y Sanz cccviII). Entre lo que recibió el obispo, se encontraba un anillo pontifical, una cruz pectoral, un báculo de plata, seis altares con sus manteles para dos iglesias, doce candelabros, tres cruces pequeñas y una grande de plata y seis cruces de bronce, cinco cálices de plata y un cáliz dorado ("Cosas que han de hacer comprar y proveer para el obispo Juan Quevedo, 20-8-1513”, cit. en Serrano y Sanz Dxxxiv).

En I5I4 llegaron a Santa María de la Antigua, para servicio de la iglesia, catorce clérigos (AGI, P, 233, leg. I, ff. 57 v., I58 r.). La organización religiosa 
estaba conformada por el obispo fray Juan de Quevedo, el deán, el arcediano, el chantre, el maestrescuela, varios canónigos, tres sacristanes y el arcipreste (“Ordenanza del rey, 5-9-I5I3", cit. en Serrano y Sanz cccix).

Era costumbre en ese entonces enterrar a los muertos en las iglesias. El segundo gobernador, Lope de Sosa, quien murió a bordo de la carabela en la que estaba llegando al puerto de la Antigua, fue enterrado en la catedral al pie del altar mayor (Santa Teresa 40: 49I).

En I519, el rey autorizó el traslado de la iglesia catedral a Panamá (Santa Teresa 4I: 37I), sin embargo, dicho traslado no fue inmediato.

\section{Casa de la Contratación}

En la Casa de la Contratación se administraban las provisiones que llegaban a la ciudad. Primero llegaban al Toldo, la bodega que quedaba en el puerto marítimo, y luego se llevaban por río hasta la Casa de la Contratación. Una vez allí, el factor, Joan Tavira, se encargaba del registro de ingreso y de la supervisión (Fernández de Oviedo, Historia general 3: 36-43). Esta casa seguramente quedaba cerca al río, para la facilidad del transporte.

Las crónicas cuentan sobre una discusión que tuvieron Pedrarias Dávila y el obispo Quevedo en la Casa de la Contratación:

se levantó de su asiento en la sala de la casa de la Contratación en la Antigua en donde se tenía la consulta, diciendo que provisiones y burlerías aquellas eran de esperarse de tal gobernador, y se salió a la plaza en medio del pueblo allí reunido. (AGI, 2-5-I/6, cit. en Santa Teresa 4I: II9)

Ello significa que dicho edificio en Santa María, al igual que en muchas otras ciudades de la Colonia temprana (Lucena 69), estaba ubicado sobre la plaza principal.

En la Casa de la Contratación había control día a día en el libro general de despachos, de todo lo que ingresaba o se vendía. Se había ordenado tener un arca para guardar todos los documentos y ordenanzas. Allí se almacenaron las provisiones que llegaron con la armada de Pedrarias Dávila y las que provenían de La Española, San Juan, Cuba y Jamaica. Era obligación pregonar las mercancías que llegaban a todos los pobladores (“R. C. 30-6-I5I3", cit. en Serrano y Sanz Dxxiv). 


\section{Casa del Cabildo}

Es probable que la Casa del Cabildo quedara sobre la plaza principal (Lucena 69), y se le había asignado por lo menos un solar:

[...] Dice que en el repartimiento de Vuestra Altezas le mandó hacer, señaló para la iglesia de Santa María de la Antigua cuatro solares y para la Casa de la contratación y fundición señaló otros solares, y para el Regimiento y Cabildo y para su persona y Oficiales de Vuestra Alteza y Justicia [...] (“Carta de Pedrarias al rey, 8-I2-I5I5", cit. en Medina 2: 22I)

\section{Monasterio de San Francisco}

El monasterio, convento e iglesia de San Francisco es nombrado por los cronistas y en las relaciones de la Colonia. Rodrigo de Colmenares llegó a Santa María con víveres para Nicuesa al poco tiempo de que se establecieron Balboa y sus hombres en I5IO. En su memorial, relata que se había construido un monasterio de franciscanos por los primeros que llegaron al Darién (Colmenares, cit. en Santa Teresa 40: 418).

Cuando el bachiller del Corral, Gonzalo de Badajoz, junto con Alonso de la Rúa y Luis Mercado quisieron alzarse contra Balboa, este los encarceló en la plaza, y al ser liberados se refugiaron en el monasterio de San Francisco, donde había tres o cuatro frailes. Este episodio tuvo lugar a finales de I5I2, pues Balboa en su carta del 2 de enero de 1513 hace referencia a este acontecimiento ocurrido "los días pasados" (AGI, "Descripciones y poblaciones", leg. 7, cit. en Santa Teresa 40: 419) ${ }^{4}$.

En un informe de 1515, Pedrarias Dávila y sus oficiales informaban al rey de que en Santa María se había hecho un monasterio de San Francisco en el que había seis religiosos que pasaban muchas necesidades, y solicitaban que se mandara a dar limosna y ayudas (AgI, Patronato, I-I-I/25, cit. en Santa Teresa 40: 97). Rodrigo de Colmenares también daba cuenta de su pobreza y de que

4 Según el historiador José Toribio Medina, cuando los presos fueron liberados, no pudieron refugiarse en el monasterio de San Francisco, pues no estaba construido en ese entonces. La construcción, según él, se terminó a finales de 1515, al igual que la iglesia catedral: "Además de esos clérigos, fueron también seis frailes franciscanos, que tenían ya concluido de hacer su convento al mismo tiempo que la iglesia catedral" (“Carta de Pedrarias, II-5-1515”, cit. en Medina I: I82). Sin embargo, podría tratarse de una segunda edificación del monasterio, así como ocurrió con la iglesia. 
el rey anualmente les mandaba ocho botas ${ }^{5}$ de harina, cinco de vino, algunos tocinos, aceite, vinagre, habas, garbanzos y otros alimentos (Colmenares, cit. en Santa Teresa 40: 419).

Pedrarias Dávila informó al rey que el monasterio estaba en un muy buen lugar y bien hecho, y que el padre fray Diego de Torres hacía un buen trabajo. Le solicitó limosna y algunos indios pequeños de las entradas para ayudar a los franciscanos (AGI, Patronato, I-I-I/26, cit. en Santa Teresa 4O: 420). Es probable que el monasterio fuera edificado en una de las tres alturas principales de la ciudad (Sarcina, De la gloria I58-160).

En el monasterio se educaba a nińos indígenas. Gaspar de Espinosa, de su segunda expedición en I519, relató la traída de los hijos del cacique Natá al convento o colegio indígena de los franciscanos de Santa María (Santa Teresa 40: 447).

\section{Iglesia de San Sebastián}

Los primeros relatos que señalan la existencia de la iglesia San Sebastián se refieren a lo ocurrido a mediados de I5II, cuando llegaron los náufragos de Nicuesa. Balboa y los hombres que ya estaban en Santa María juraron en la iglesia de San Sebastián no recibirlos:

[...] teniéndolo muy bien amasado, juntaron el pueblo, prevenidos los de su opinión, y en la iglesia de San Sebastián pusieron al pié del altar una manta ó tapete en tierra y una almohada de cama y encima una cruz, como se suele hacer el jueves de la cena, o viernes santo, cuando se andan las estaciones; y juraron allí solemnemente sobre aquella cruz que no recibirían a Diego de Nicuesa. (Fernández de Oviedo, Historia general 2: 471-478)

No se sabe la fecha exacta de este juramento, pero Diego de Nicuesa fue expulsado de Santa María de la Antigua en un barco que salió de aquel puerto el I9 de marzo de I5Ir. Balboa lo tuvo quince o veinte días en su casa antes de enviarlo a su suerte en el mar. Por lo tanto, Nicuesa estuvo en la ciudad en los primeros días de febrero y el juramento en la iglesia de San Sebastián probablemente se hizo en el mes de enero o febrero de ese año. En consecuencia, la

5 Medida de capacidad que se utilizaba en las embarcaciones.

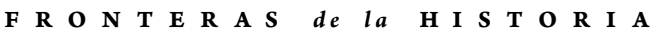


iglesia de San Sebastián ya existía a los seis meses de haber entrado Balboa, Enciso y los hombres de Ojeda en el Darién (Santa Teresa 40: 498).

Oviedo reporta que se celebraban misas en la cofradía de San Sebastián y que esta se encontraba en las afueras de la ciudad, en uno de sus extremos (Fernández de Oviedo, Historia general 3: 83-86). Gracias a Oviedo, también sabemos que la cárcel quedaba junto a la iglesia y que frente a esas edificaciones quedaba su casa (Fernández de Oviedo, Historia general 3: 88-93).

\section{Hospital de Santiago}

Con la llegada de Pedrarias Dávila, el rey mediante una real cédula ordenaba la construcción del hospital de Santa María de la Antigua, para atender a los enfermos y albergar a los más pobres. Para dicho hospital se mandaron a hacer cincuenta camas de las mismas que se utilizaban en Sevilla ("Libro de despachos de Tierra Firme”, AgI, IO9-I-5, cit. en Santa Teresa 40: 474).

El hospital fue terminado, al igual que la iglesia catedral, a finales de 1515 . Dávila había solicitado que de las entradas se le destinaran recursos. Balboa y sus hombres contribuyeron con objetos indígenas que traían de su segundo viaje al Mar del Sur ("Carta de Pedrarias, 28-I2-I5I5", cit. en Medina I: I82). Era una edificación grande compuesta por varias casas, entre ellas la botica y la capilla ("Acuerdos de la administración de Castilla del Oro, 8-3-I515", cit. en Medina 2: 498).

El clérigo Hernando de Luque fue uno de los mayordomos del hospital:

Entre los clérigos que embarcaron con Pedrarias, no podemos dejar de citar a Hernando de Luque, el futuro socio de Pizarro y Almagro (que también vinieron entonces) que sirvió en el Darién de doctrinero y especialmente en el Hospital del cual fue mayordomo. (AGI, 52-I-I/25, cit. en Santa Teresa 4I: I88)

Otro mayordomo fue Antón de Vega, quien tenía indígenas esclavos que ayudaban con los enfermos ("Trata de esclavos indios, I5I4", cit. Friede I: 49).

El hospital de Santa María de la Antigua estaba bajo el patrocinio del apóstol Santiago, cuya imagen reposaba en el altar de la capilla (Santa Teresa 40: 480).

El rey Fernando, en una carta del 9 de agosto de 1513 , recomienda a los oficiales de Sevilla llevar en la expedición a un boticario. No obstante la prohibición de dar pasaje a los extranjeros, el rey por real cédula autorizó el viaje 
del boticario italiano Francisco de Cota ("Libro de despachos de Tierra Firme", AGI, I09-I-5, cit. en Santa Teresa 40: 475).

\section{La Casa de la Fundición Real}

En la Casa de Fundición de Santa María de la Antigua se fundía el oro de las minas y las entradas, se construyó con la llegada de la armada, y como veedor fue nombrado Gonzalo Fernández de Oviedo. En julio de I5I4 ya existía dicha casa (AGI, Carta, 28-I-I5I6, cit. en Santa Teresa 4I: II7).

Había en esta edificación todas las herramientas necesarias para la fundición: hornos, yunque y martillo y un libro en el que se anotaba cada fundición y las cantidades de oro que salían, al igual que el quinto que le pertenecía a la Corona ("Instrucciones del rey al veedor Juan Manuel de Cartagena", cit. en Friede I: I37-I38). Alonso de La Puente llevaba en su contabilidad datos sobre costos de la casa y su mantenimiento ("Cargo que hizo Alonso de la puente I5I4-I520", cit. en Medina 2: 422- 427).

Según una real cédula, se debía hacer dos o tres fundiciones al año, en las cuales debía estar presente el gobernador y sus oficiales para que no se generaran rumores. Por orden del rey, no se podía labrar ningún objeto para uso en Santa María, a fin de que a España llegara la mayor cantidad de oro posible (“R. C., 30-7-I5I3", cit. en Serrano y Sanz DxxviI).

En I52I mediante real cédula, se ordenaba que la Casa de la Fundición se trasladara a Panamá. Sin embargo, en 1524 todavía no se había realizado el traslado, por lo que se ordenaba hacerlo nuevamente (AGI, $P$, 233, leg. I, f. 29I r.-v.).

\section{El taller del herrero}

Las recientes investigaciones arqueológicas han evidenciado la presencia de un taller de herrería en una parte central de la ciudad, ubicada en un llano bajo y anegadizo. El envío de una gran cantidad de hierro con la flota de Pedrarias Dávila para la construcción de "dardos y otras cosas" es un hecho conocido (Mena 105). Ahora se sabe que uno o varios herreros estaban activos en la ciudad y que utilizaban hornos bastante sencillos, en piedras de río de medianas dimensiones, con una boca central, utilizados para arreglos de objetos dañados o pequeños trabajos. Se sabe que fueron ciertamente procesados aquí, entre otros artículos, los cubos de hierro contenidos en las balas de falconete y los clavos (Sarcina, De la gloria IO3-IIO). 

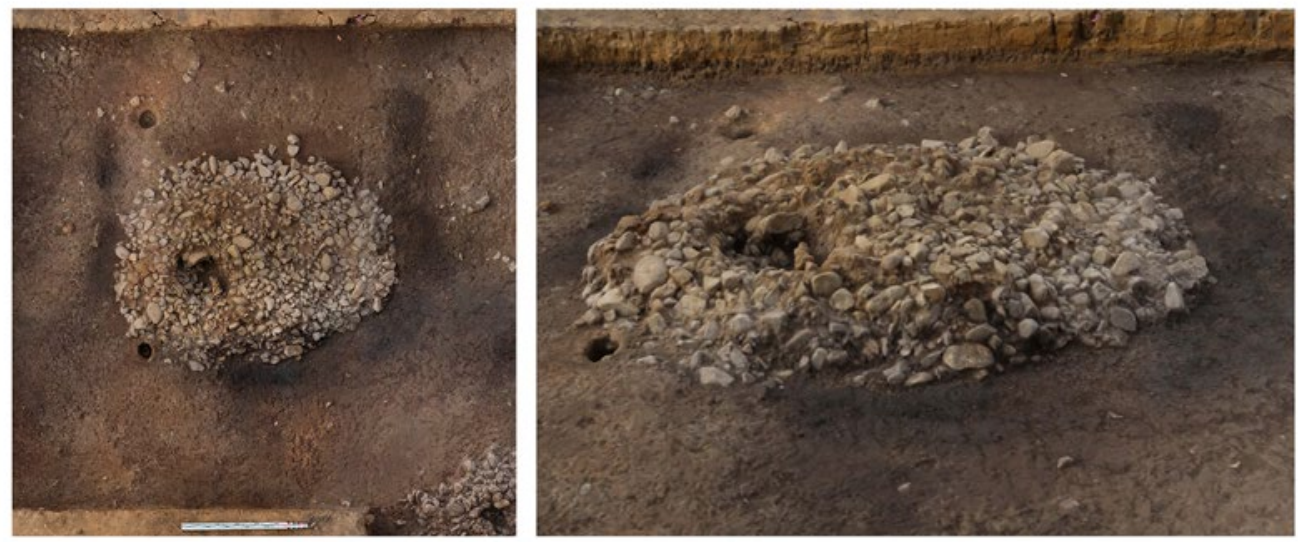

$\rightarrow$ FIGURA I.

Santa María de la Antigua del Darién: taller del herrero

Fuente: fotografía de Alberto Sarcina.

\section{Cárcel}

Como se mencionó, la cárcel quedaba junto a la iglesia de San Sebastián y también frente a la casa de Oviedo, a las afueras de la ciudad:

[...] venian del campo, a medianoche, aquel Simón Bernal que os acuchilló, e Julián Gutiérrez, criado del bachiller Diego de Corral, e junto a la iglesia de Sanct Sebastián habló a Joan Rodríguez Ortolano, el cual, por la calor estaba a la puerta de la cárcel, donde está preso; e como éstos llegaron, le hablaron [...] E diciendo esto, seńalaba con el dedo la ventana que se vía desde allí, y era la camara donde yo (Oviedo) dormía, e muchas veces, de noche, me paraba alli desnudo por el calor. [...] E así volvió las espaldas él y el Julián e se entraron en la cibdad [...] (Fernández de Oviedo, Historia general 3: 88-93)

\section{Panadería, pescadería, carnicería y plaza de abastos}

Se tiene noticia de estas edificaciones gracias a la carta que Pedrarias Dávila le envió al rey en $\mathbf{5}$ I9, en la cual refería que en la ciudad había carnicería, pescadería y panadería (“Carta de Pedrarias al rey, 25-II-I5I9", cit. en Santa Teresa 4I: 384). 


\section{Puerto y Toldo}

El puerto de Santa María no quedaba en el pueblo, sino en la desembocadura del río Darién, que en ese momento salía al mar. El río Darién es el actual río Tanela, su curso ha cambiado en el transcurso de los siglos, hoy desemboca en la ciénaga de Marriaga. Recientemente, gracias al estudio de las imágenes satelitales y a investigaciones en campo, se ha podido reconstruir el curso original de dicho río, que pasaba con su cauce principal al norte del poblado y de la ciudad. Sin embargo, el río tenía allí una bifurcación y uno de sus brazos bordeaba el lado occidental de la ciudad, en tanto que el otro la cortaba en dos partes (Sarcina, "Santa María de la Antigua del Darién, la primera" 292-294). La desembocadura del río quedaba más o menos a "legua y media" del pueblo (Andagoya 94).

\section{Los alrededores}

Los alrededores se habían destinado para haciendas y tierras de cultivo ("Probanza, I517", cit. en Santa Teresa 40: 59-60).

\section{Edificios privados}

En las crónicas se identifican algunas casas de pobladores españoles. La casa de Oviedo, una de las edificaciones más importantes y bien hechas de la ciudad, quedaba sobre una de las orillas del río y tenía dos pisos, varias habitaciones y una huerta grande donde había sembrados árboles de naranja, cidros y limones, "y por una parte del dicho huerto un hermoso río y el sitio muy gracioso y sano, y de lindos aires y vista sobre aquella ribera” (Fernández de Oviedo, Sumario 135).

Balboa poseía un solar sobre la plaza principal donde tenía construidas dos casas, una de las cuales tenía arrendada a 500 pesos, en tanto que en la otra vivía él. Cuando Pedrarias Dávila llegó a Santa María obligó a Balboa a venderle su casa a un precio menor que un alquiler (AGI, Patronato, 2-2-I/I4, cit. en Santa Teresa 40: 284).

La casa del tesorero Alonso De la Puente quedaba en dos solares de la Corona que se cercaron con maderas y cańas. Esta pequeńa casa de dos pisos se construyó para proteger el oro y las escrituras reales de la lluvia, los incendios 
y los robos. Es la única casa de la que se tiene registro que haya sido construida de tapia, barro y madera ("Probanza sobre necesidades de la Casa Real, I520", cit. en Friede I: 70-73).

El capitán Rodrigo de Colmenares se estableció en Santa María antes de la llegada de Pedrarias Dávila, era de los más favorecidos por Balboa y contaba con varias haciendas, cultivos y muchos indios de servicio (Las Casas 4: 96).

El licenciado Gaspar de Espinosa, alcalde mayor de Castilla de Oro, había llegado con la armada de Pedrarias Dávila y tenía una casa donde en ocasiones hacían reuniones las principales autoridades de la ciudad ("Testimonio de Cristóbal Muñoz, escribano público del Consejo de Santa María”, cit. en Santa Teresa 40: 5II).

Diego del Corral y Lope de Olano eran vecinos de solar. La casa de Lope de Olano era una de las mejores que había en Santa María antes de la llegada de Pedrarias ("Enciso, I525", cit. en Medina I: 218).

El bachiller Diego del Corral vivía con una mujer indígena y el hijo que había tenido con ella, a pesar de estar casado en España. Cuando Oviedo tuvo a su cargo la gobernación de Santa María de la Antigua, decía que la casa del bachiller era asilo de espías de los indios sublevados (Fernández de Oviedo, Historia general 3: 94-96). Aparte de la hacienda que Diego del Corral tenía en Santa María, poseía una estancia a media legua de la ciudad (Fernández de Oviedo, Historia general 3: 78-82).

En la casa del contador, Diego de Márquez, se llevaban todas las cuentas de la Corona y la relación de muchos acontecimientos importantes en Santa María de la Antigua ("Acuerdos de la administración de Castilla del Oro, 2-8-I5I5", cit. en Medina 2: 495).

La custodia de los esclavos de la Corona se realizaba en la casa de Blas de Bastos. Cuando algún indio o india se moría o se escapaba, a falta de escribanos, se llamaba a la persona más cercana como testigo. Por lo general, eran los vecinos más próximos: el tesorero Andrés de Cereceda, Alonso de Cáceres, Pedro Alonso de Zafra, Fernando de Zafra o Antón de Trigueros ("Información sobre pérdida de indios, I520", cit. en Friede I: 62-63). 


\section{Consideraciones finales}

La población que habitó la ciudad de Santa María de la Antigua del Darién, tras la conquista del poblado indígena de habla cueva que, como hemos visto, debió de llamarse Darién, al igual que el río que corría a sus lados y se dividía en al menos tres brazos, tuvo que pasar por cambios en el transcurso de su corta existencia.

A los "quinientos y quince hombres" españoles y sus "más de mil y quinientos indios e indias naborias" que los servían (Fernández de Oviedo, Historia general 3: 34) presentes a la llegada de la armada de Pedrarias Dávila se sumaron de repente más de 2000 personas procedentes de la península ibérica que, sin duda, necesitaron de otro gran número de servidores nativos. Este número no es reportado por ningún cronista, sin embargo, no es descabellado pensar en que el asentamiento, en su momento de auge correspondiente a su nombramiento como ciudad y capital de Castilla del Oro, en 1514, tuvo que albergar alrededor de 5000-5500 personas, entre castellanos, servidores de origen africano que llegaron con sus amos desde Espańa y servidores, o naborías, indígenas.

De las recientes investigaciones arqueológicas sabemos que algunos de los servidores indígenas vivían dentro de la ciudad, en pequeñas casas de madera colindantes a los solares de los europeos (Sarcina, "Santa María de la Antigua del Darién: The Aftermath” I8I-I83). La gran mayoría de la loza utilizada por los habitantes - españoles e indígenas - fue de manufactura indígena. La cerámica de origen europeo fue muy escasa en la ciudad y, probablemente, con excepción de las botijas y de los lebrillos ${ }^{6}$ para higiene personal, se utilizaba tan solo en las ocasiones más importantes (Sarcina, De la gloria 57-63). También se tiene información sobre el tamaño de la ciudad, ya que el área de dispersión del material arqueológico relativo al asentamiento alcanza las 33 hectáreas (Sarcina, "Santa María de la Antigua del Darién, la primera" 28I-283).

En la primera fase del asentamiento, correspondiente al gobierno de Vasco Núnez de Balboa, se tuvo que adaptar el poblado preexistente a las normas de los recién llegados. En ese primer momento se construyó la capilla dedicada a la Virgen de la Antigua sobre la casa del cacique Cemaco, y en el mismo lugar se construyó la primera plaza, con la Casa del Cabildo y la del propio Balboa.

6 Vasija ancha y baja de barro vidriado que sirve para lavar ropa y para la higiene personal. 
Mientras tanto, en las otras alturas principales del antiguo poblado se fundaron el monasterio de San Francisco y la iglesia de San Sebastián.

La llegada del nuevo gobernador Pedrarias Dávila, de sus capitanes y de las 2000 personas procedentes de Sevilla, no solo supuso un cambio político sustancial, especialmente con respecto a las poblaciones nativas, sino también un intento de poner en práctica el ideal de la cuadrícula de origen grecorromano en la reciente fundación. Un ideal que acababa de resucitar en el mundo europeo del Renacimiento y que situaba en el centro de la cuadrícula los palacios que simbolizaban el poder religioso y político (Aprile-Gniset 206). Sin embargo, como se ha mostrado aquí, a juzgar por la calle occidental de la ciudad, el intento no parece haber tenido éxito, derrotado por la morfología y el clima de la región (Sarcina, De la gloria I45-169).

En aquella época, que corresponde al "auge" de la ciudad, se reorganizó la plaza, se construyó la Casa de la Contratación, la Casa de la Fundición, el hospital, se transformó la capilla en catedral y se amplió el monasterio de San Francisco. También se construyó la casa del tesorero Alonso de la Puente, la única edificación de la que se tenga conocimiento hasta ahora construida en tapias, para la protección del oro y las escrituras de la Corona. Además, la presencia de las panaderías, de la pescadería y de la plaza de abastos se conoce desde dicho periodo.

El auge no duraría mucho, ya que la decisión de mover la capital y los cargos principales de la ciudad a la recién fundada Panamá, en I519, determinó el comienzo del fin. Paulatinamente, los habitantes de Santa María de la Antigua se movieron hacia Panamá, Nombre de Dios y Acla, todas fundadas -o refundadas en el caso de Nombre de Dios- entre is I5 y I519.

El periodo entre 1520 y 1524 corresponde, entonces, a una fase de decadencia de la ciudad, con el abandono de la mayoría de las casas y la reutilización, por parte de los ciudadanos restantes, de los materiales abandonados, como clavos y ladrillos. Estos últimos sirvieron originalmente para los pisos y en esta fase se reutilizaron a veces tan solo para rellenar y drenar las zonas de estancamiento de agua (Sarcina, De la gloria 93-IO3).

En un esfuerzo por entender el plano de Santa María de la Antigua, del que por el momento no se conoce ningún ejemplar, es posible buscar paralelismos con planos de ciudades contemporáneas, y en particular de Panamá, construida por el mismo Pedrarias Dávila.

Cuando inició la conquista de Tierra Firme no se disponía de una precisa y clara legislación urbana. Fue tan solo en I5I4 que se introdujeron las primeras 
normas en el territorio, para definir el lugar en el que se debía ubicar la plaza, la iglesia y el tamaño de los solares, con la ordenanza dirigida por el rey a Pedrarias Dávila del 4 de agosto de I5I3 (“R. C. I513", cit. en Santa Teresa 40: 322). La implementación urbana de Panamá fue regulada por las mismas instrucciones dadas a Pedrarias Dávila en I513, y que debían aplicarse para todo el poblamiento de Castilla del Oro (Lucena 43).

Se sabe de la presencia en Tierra Firme en estos primeros ańos de Alonso García Bravo, un experto en geometría y mensura de terrenos, conocido por haber realizado el primer trazado de Ciudad de México, y que se embarcó hacia las Indias Occidentales justamente con la armada de Pedrarias Dávila en I5137. Es entonces posible que haya reformado el trazado inicial de Santa María de la Antigua, y que ayudara al trazado de Acla (Lucena 44). De alguna manera, la experimentación en Santa María de la Antigua fue la guía para trazar las nuevas ciudades de Panamá, Acla y Nombre de Dios, a efectos de tener referentes sobre la ubicación de las instituciones. Los planos de la primera Panamá (véase figura 2), como el de Bautista Antonelli de 1586, muestran una ciudad ortogonal, pero con calles no muy rectas, trazas irregulares y manzanas y solares de distintos tamaños. El trazado de Santa María de la Antigua tuvo que ser aún más irregular y debía tener algunas características relacionadas con las ciudades fundadas sobre ríos, pues como se ha visto, uno de los brazos del río Darién bordeaba la ciudad (Aprile-Gnisset 198; Sarcina, De la gloria I5I).

La Isabela, primera fundación europea en el continente en la isla La Española en 1494, tampoco tenía una traza regular: "los edificios principales estaban alineados en ángulos únicos en relación con el norte, sin que haya dos estructuras que compartan la misma orientación" (Deagan y Cruxent, cit. en Sarcina, De la gloria I5I). De igual manera, Santo Domingo y Panamá tampoco contaban con una cuadrícula perfecta y se trataba más bien de fundaciones que se adaptaron y moldearon su trazado siguiendo la topografía del lugar donde se ubicaron (Sarcina, De la gloria I5I). La implementación de la cuadrícula se fue perfeccionando en fundaciones como Natá (I522) en Nicaragua — que al igual que Panamá, fue fundada por Pedrarias Dávila - donde se implementó una revolucionaria traza de cuadrícula con manzanas de mayor tamaño (Tejeira 4I).

7 En la Información de méritos y servicios de Alonso García Bravo, alarife que trazó la ciudad de México, se lee que García Bravo acompañó a Pedrarias Dávila en su expedición de 1513 y se quedó en Tierra Firme, o sea, en Santa María de la Antigua y en Acla, hasta 1517, año en que viajó a Jamaica (Touissant y Mantecón 96). 


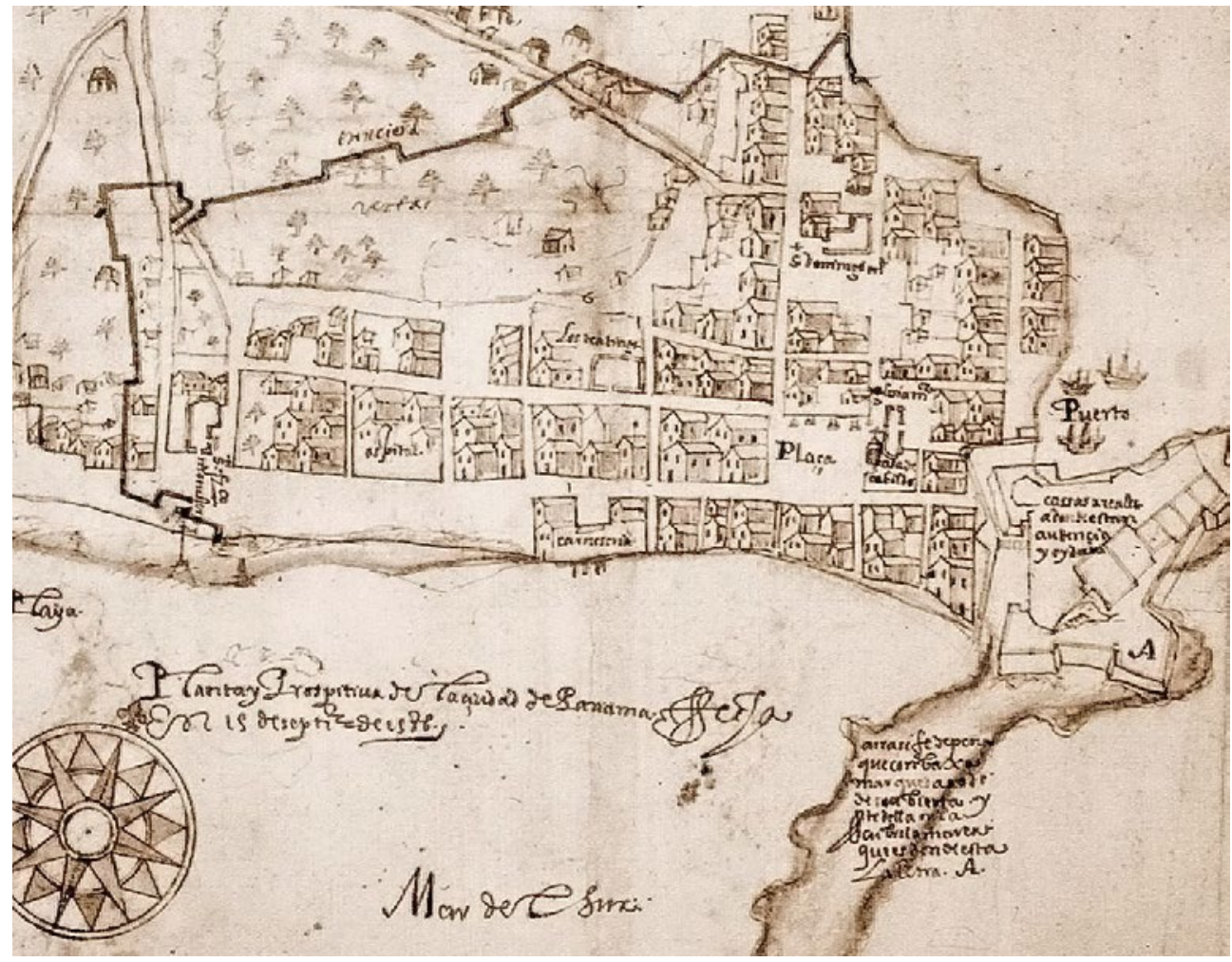

\section{$\rightarrow$ FIGURA 2.}

Plano de Panamá de I586 (detalle) - Juan Bautista Antonelli

Fuente: Ministerio de Defensa (España), Archivo del Museo Naval (AMN), I3-D-I7.

Existe una relación entre el desarrollo urbano y el control territorial, que corresponde a la posibilidad de intervenir el territorio mismo (por ejemplo, drenando una zona pantanosa) o a la posibilidad de elegir el lugar más adecuado para una fundación. Por supuesto, esto también tiene que ver con el control militar del territorio: más control significa más opciones. En una situación de inseguridad, la fundación de un asentamiento se realiza casi siempre en alturas fácilmente controlables y defendibles. Solo el control total de un territorio permite la fundación de ciudades en las llanuras y, en consecuencia, la posibilidad de aplicar la cuadrícula perfecta.

La secuencia que en Tierra Firme empieza por Santa María de la Antigua y termina en Natá, es un reflejo del creciente control territorial por parte de los españoles sobre el antiguo territorio cueva. Como se ha visto, Santa María de la Antigua debió tener una cuadrícula aproximada, condicionada por la fundación indígena anterior y por la morfología del territorio. No se trató de 
una fundación nueva, como San Sebastián de Urabá, sino de una conquista forzada por la necesidad. Se tuvo que ajustar, necesariamente, a un patrón de asentamiento prehispánico, que se desarrollaba en las alturas y, en el momento de su ampliación y regularización, se vio obligada a ocupar las tierras aluviales entre colina y colina (Sarcina, De la gloria 158 ).

De Acla, fundada en 1515 , no se sabe casi nada, mientras que de Nombre de Dios (figura 3), refundada por Pedrarias Dávila en 1519, hay algunas representaciones. Por lo que se deduce, tuvo que ser un puerto muy condicionado por la morfología del territorio, apretado entre altas montańas, el mar y dos ríos. Panamá pudo conformarse en una cuadrícula un poco más regular pero, como se ha visto, aún lejos de ser perfecta.

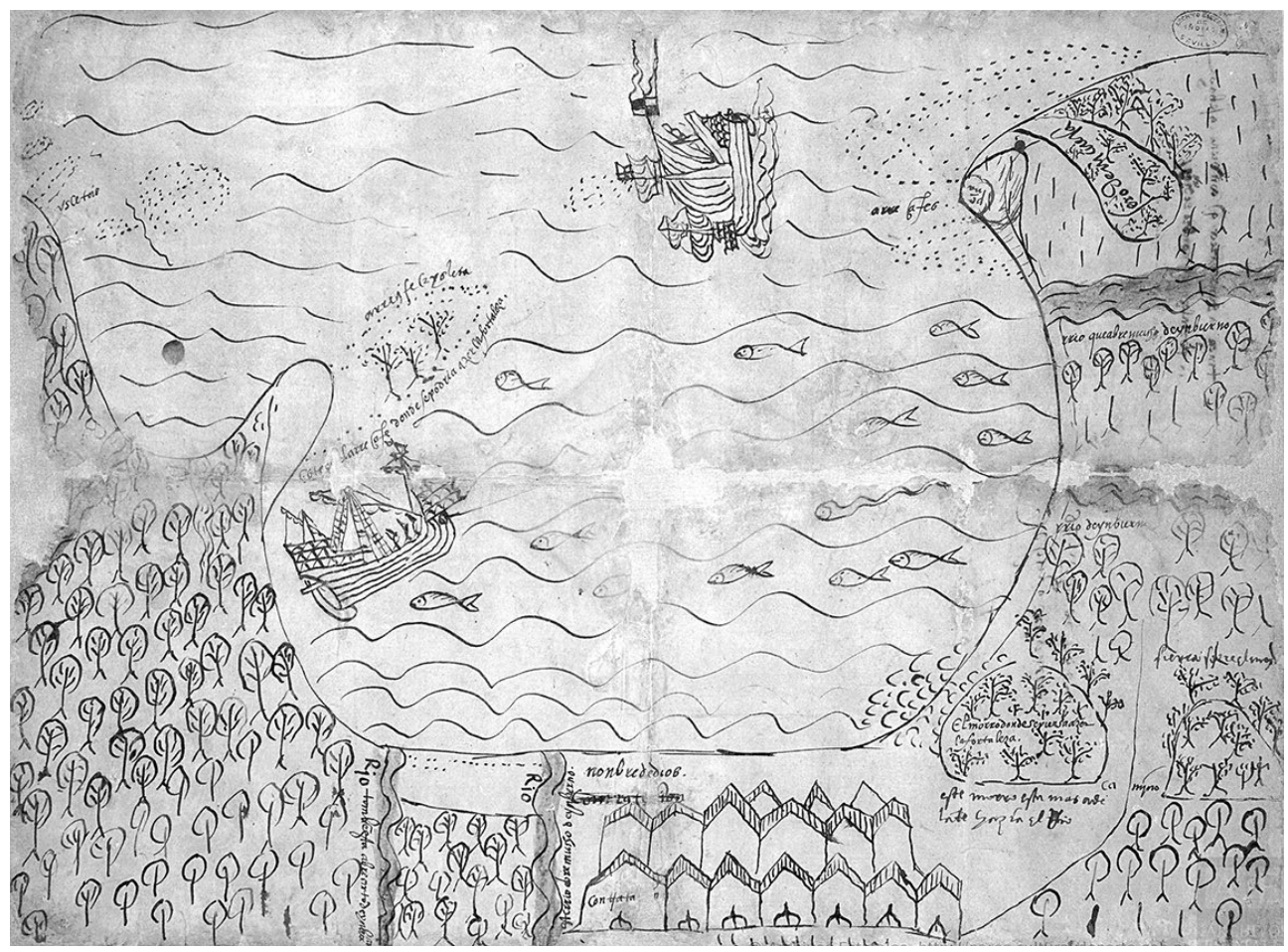

$\rightarrow$ FIGURA 3 .

Plano del licenciado Vaca de Castro

Fuente: AGI, (P), mapa I. I54I. 
Fue tan solo en I522, cuando el control español sobre el istmo se había hecho (temporalmente, al menos) estable, que se logró fundar la ciudad de Natá en un terreno completamente plano, con una cuadrícula casi perfecta de amplias manzanas cuadradas (Tejeira 60-64).

En tal sentido, Santa María de la Antigua representa el eslabón perdido de la urbanística de la Colonia temprana de Tierra Firme. En esta contribución se ha intentado recopilar datos conocidos, menos conocidos y nuevos, para dar un primer paso hacia la reconstrucción de un posible plano de la ciudad.

Al mismo tiempo, nos pareció importante esbozar una idea de las relaciones que se dieron entre los diversos actores, principalmente indígenas y españoles, dentro y fuera de la ciudad, ya que estas relaciones, conjuntamente con las diferentes políticas hacia los habitantes nativos de la región, tienen una incidencia directa en la conformación misma de la ciudad.

\section{\%}

\section{$\begin{array}{llllllllllll} & \boldsymbol{I} & \mathbf{B} & \mathbf{L} & \mathbf{I} & \mathbf{O} & \mathbf{G} & \mathbf{R} & \mathbf{A} & \mathbf{F} & \mathbf{I} & A\end{array}$}

\section{I . F U E N T ES PR I M A R I S}

\section{A. Archivos}

Archivo General de Indias, Sevilla, España (AGI).

$$
\begin{aligned}
& \text { Panamá (P) } \\
& \text { 233. }
\end{aligned}
$$

Mapa I. I54I.

\section{I. FU E N T ES SECUNDARIAS}

Andagoya, Pascual de. Relación y documentos. Crónicas de América, editado por Adrián Blázquez. Madrid: Historia 16, 1986.

Anglería, Pedro Mártir de. Décadas del Nuevo Mundo. Madrid: Polifemo, 1989.

Aprile-Gniset, Jaques. La ciudad colombiana. Prehispánica, de conquista e indiana. Bogotá: Banco Popular, ı991. 
Fernández de Oviedo y Valdés, Gonzalo. Historia general y natural de las Indias, islas y tierra firme del mar Océano. 4 vols. 1535. Madrid: Imprenta de la Real Academia de la Historia, 185 I-1855.

--.- Sumario de la natural historia de las Indias. Ciudad de México: Fondo de Cultura Económica, 1950.

Friede, Juan, editor. Documentos inéditos para la historia de Colombia. Vol. I. Bogotá: Academia Colombiana de Historia, 1955-1960.

Las Casas, Bartolomé de. Historia de las Indias. Vols. 3, 4 y 5. Madrid: M. Ginesta, 1875-1876.

Lucena Giraldo, Manuel. A los cuatro vientos: las ciudades de la América hispánica. Madrid: Marcial Pons, 2006.

Medina, José Toribio. El descubrimiento del océano Pacífico: Vasco Núñez de Balboa, Hernando de Magallanes y sus compañeros. Vols. I y 2. Santiago de Chile: Imprenta Universitaria, I913.

Mena García, Carmen. Sevilla y las flotas de Indias. Sevilla: Universidad de Sevilla, Secretariado de Publicaciones, 1998.

Navarrete, Martín Fernández de. Colección de los viajes y descubrimientos que hicieron por mar los españoles desde fines del siglo XV: con varios documentos inéditos concernientes á la historia de la marina castellana y de los establecimientos españoles en Indias. Vols. I, 2 y 3. Madrid: Imprenta Real, I825-1837.

Santa Teresa, fray Severino de. Historia documentada de la iglesia en Urabá y el Darién; desde el descubrimiento hasta nuestros dias. Vols. 40, 4I y 42. Bogotá: Kelly, I956-1957.

Sarcina, Alberto. De la gloria al olvido: estudio arqueológico de la primera ciudad española en la Tierra Firme de América: Santa María de la Antigua del Darién. Leiden, Países Bajos: Archaeological Studies Leiden University; Leiden University Press, 2020.

---. "Santa María de la Antigua del Darién, la primera ciudad española en Tierra Firme: una prospección arqueológica sistemática”. Revista Colombiana de Antropología, vol. 53, n. ${ }^{\circ}$ I, 2017 , pp. 269-296, https://doi.org/10.22380/2539472X.II

---. "Santa María de la Antigua y Darién. Las dos caras de la primera ciudad europea en tierra firme". Indiana, vol. 35, n. 2 2, 2018 , pp. 243-269.

--.. “Santa María de la Antigua del Darién: The Aftermath of Colonial Settlemen en Material Encounters and Indigenous Transformations". Early Colonial Americas, editado por C. L. Hofman y F. W. H. Keehnen. Leiden-Boston: Brill, 2019, pp. 175-196.

Sarcina, Alberto y Carolina Quintero. Las cuatro vidas de Darién. Bogotá: Instituto Colombiano de Antropología e Historia (ICANH), 2018. 
Serrano y Sanz, Manuel. Origenes de la dominación española en América: estudios históricos. Madrid: Baylly Bailliére, I9I8.

Tejeira Davis, Eduardo. "Pedrarias Dávila y sus fundaciones en Tierra Firme, 1513-1522". Anales del Instituto de Investigaciones Estéticas, n. ${ }^{\circ}$ 69, 1996, pp. 41-77.

Touissant, Manuel y José Ignacio Mantecón Navasal. Información de méritos y servicios de Alonso García Bravo, alarife que trazó la ciudad de México. Ciudad de México: Imprenta Universitaria, 1956. 